\title{
The use of a modification of the Patient Enablement Instrument in asthma
}

\section{John Haughney ${ }^{a, *}$, Philip Cotton ${ }^{b}$, Jan-Paul Rosen ${ }^{a, c}$, Ken Morrison ${ }^{c}$, David Price ${ }^{a}$}

\author{
a Department of General Practice and Primary Care, University of Aberdeen, UK \\ b Section of General Practice and Primary Care, University of Glasgow, UK \\ c AstraZeneca UK Ltd, Horizon Place, Luton, UK
}

Received 2nd August 2006; accepted 10th November 2006

\author{
KEYWORDS \\ Asthma; \\ Validation studies; \\ Enablement; \\ Self management plan
}

\section{Introduction}

Personal asthma action plans, agreed between patient and clinician, are acknowledged as a valuable intervention in asthma treatment, and national and international guidelines advocate their use. ${ }^{1}$ These plans usually encourage patients

\footnotetext{
* Corresponding author.

Department of General Practice and Primary Care, Foresterhill Health Centre, Westburn Road, Aberdeen AB25 2AY, UK

Tel: +44 (0)1224 554588; fax: +44 (0)1224 550683

E-mail address: j.haughney@abdn.ac.uk
}

\begin{abstract}
Aim: To ascertain if the Patient Enablement Instrument (PEI) could be adapted for use in asthma management, and to use it to evaluate "enablement" in patients with asthma randomised to either a fixed or adjustable medication dosing regime. ethods: The original Patient Enablement Instrument was modified by making a minor were recruited to the study. The internal and external consistencies of the modified PEI were assessed. Individual scores were compared across treatment groups.

Results: The modified PEI had high internal consistency. There was a significant correlation between modified PEI total score and change in Mini Asthma Quality of medication dosing had a clinically relevant treatment benefit.

Conclusions: The Patient Enablement Instrument can be used to measure "enablement" in asthma.

(c) 2007 General Practice Airways Group. All rights reserved.
\end{abstract}

1471-4418 @ 2007 General Practice Airways Group. All rights reserved doi:10.3132/pcrj.2007.00014

to adjust their medication when subjective and/or objective changes in their asthma control occur. They may also promote "enablement" - a concept which may describe a patient's ability to understand better, or cope with, or participate in, or have greater responsibility for, their own care. Patient enablement may be a factor in improving compliance with therapy and therefore in improving outcomes.

The original version of the Patient Enablement Instrument (PEI) reported by Howie et $a l^{2}$ was developed and used to assess the "enablement" of patients after a consultation with their primary care clinician for an acute or chronic condition. In 
addition to it being used as a measure of the performance of individual clinicians, ${ }^{3}$ it has also been used to evaluate "enablement" in patients with cough, randomised to receive a delayed prescription for antibiotics: ${ }^{4}$ the authors drew a distinction between "satisfaction", described as occurring when expectations were met, and "enablement", occurring when benefit has been achieved. Furthermore, they argued that "the measure should centre on issues that patients identify as important rather than on issues that doctors believe to be important."

\section{Methods}

\section{Enablement assessment}

In consultation with a small group of patients, a minor change was made to the introductory statement of the original PEI ("As a result of your visit to the doctor today, do you feel you are ...") to make it relevant to chronic disease management, in this case asthma: "As a result of the treatment you have been on for your asthma, do you feel you are ...", followed by the original items:

1. able to cope with life?

2. able to understand your illness?

3. able to cope with your illness?

4. able to keep yourself healthy?

5 . confident about your health?

6. able to help yourself?

Following the scoring system described in the original PEI report, ${ }^{2}$ patients' responses were scored 0 ("same or less" or "not applicable"), 1 ("better") or 2 ("much better"). There is a minimum score of 0 and a maximum score of 12 . A PEI score of $\geq 6$ has been reported as indicating clinically meaningful "enablement". ${ }^{5}$

\section{Study design}

This study was run as a part of a large randomised multicentre open-label study to compare fixed and adjustable asthma treatment regimes. We have reported this study elsewhere. ${ }^{6}$ Patients aged 18 and over with a diagnosis of asthma for at least six months, on treatment with inhaled corticosteroids at a dose of at least 400 micrograms per day were eligible for recruitment. Patients had to be stable on this dose of inhaled steroid if they were also on treatment with a long-acting beta-agonist, or they needed their clinician to believe that they needed the introduction of a long-acting beta-agonist in addition to this level of corticosteroid treatment. In one arm of the 12-week study, patients received a fixed, regular dose of an inhaled steroid/longacting beta-agonist combination inhaler. In the other arm, patients adjusted the dose of the same combination inhaler as their symptoms varied (night time wakening and reliever usage), following a standard, written asthma management plan, without further recourse to their clinician. The modified PEI questionnaire was completed at the end of the study by 228 patients (adjustable dosing group $n=124$, fixed dosing group $n=104$ ) from 73 UK centres, who were randomly selected from those willing to participate. Patients had their asthma severity categorised (by their managing physician) according to GINA guidelines ${ }^{7}$ at entry and at the end of treatment. Ethics approval was granted by West Midlands Multicentre Research Ethics Committee as a protocol amendment, study ref: MT/AB/MREC/00/7/53a.

\section{Analysis}

Internal consistency of the modified PEI was evaluated using the Cronbach's alpha assessment. This test is a measure of the internal consistency of the responses. For comparison, the same test was also applied to the Mini Asthma Quality of Life Questionnaire (Mini AQLQ). External validity was assessed through correlation of clinical improvement in terms of the Mini AQLQ, using the Spearman rank correlation coefficient. As an exploratory item, mean total question scores were compared across treatment groups using a two-sample t-test.

\section{Results}

The subgroups were well matched for demography - see Table 1.

The modified PEI had a Cronbach's alpha score of 0.92 , indicating high internal consistency. The Mini AQLQ had a Cronbach's alpha score of 0.95.

There was no correlation (Spearman's rank correlation coefficient) between modified PEI total score and Mini AQLQ overall ( 0.13$)$ and domain scores (except symptoms) at the end of the study. However, there were significant correlations between PEI score and the change in Mini AQLQ overall and Mini AQLQ domain scores, as shown in Table 2.

A correlation between PEI total score and change in GINA severity status (as judged by the physician) from entry to the end of the study was sought. Patients whose severity status improved through the study (defined as the physician categorising the patient as moving from a worse asthma severity 
Table 1 Demographics, asthma history and baseline characteristics of subgroups

\begin{tabular}{lcc}
\hline & Adjustable dosing & Fixed dosing \\
\hline $\mathrm{n}$ (\% male) & $124(48)$ & 51.3 \\
Mean age, years & 50.4 & $2(49)$ \\
Duration of asthma, $\mathrm{n}(\%)$ & & $(2)$ \\
$\quad<1$ year & $2(2)$ & $19(18)$ \\
1-5 years & $22(18)$ & $83(80)$ \\
$\quad>5$ years & $99(80)$ & $3(3)$ \\
Symptom severity, $\mathrm{n}(\%)$ & $2(2)$ & $35(34)$ \\
$\quad$ Severe persistent & $36(29)$ & $29(28)$ \\
$\quad$ Moderate persistent & $38(31)$ & $37(36)$ \\
Mild persistent & $48(39)$ & $434.7(127.0)$ \\
$\quad$ Mild intermittent & $437.1(125.6)$ & $5.5(1.2)$ \\
Mean clinic PEF $( \pm$ SD), L/min & $5.6(1.1)$ &
\end{tabular}

Table 2 Correlation between PEI total score and Mini AQLQ

\begin{tabular}{lccccc}
\hline & $\begin{array}{c}\text { MiniAQLQ } \\
\text { overall }\end{array}$ & $\begin{array}{c}\text { MiniAQLQ } \\
\text { activity }\end{array}$ & $\begin{array}{c}\text { MiniAQLQ } \\
\text { symptoms }\end{array}$ & $\begin{array}{c}\text { MiniAQLQ } \\
\text { emotional }\end{array}$ & $\begin{array}{c}\text { MiniAQLQ } \\
\text { environment }\end{array}$ \\
\hline PEI total vs MiniAQLQ & 0.1325 & 0.1177 & $0.1537^{*}$ & 0.0964 & 0.1090 \\
PEI total vs change in MiniAQLQ & $0.3034^{* *}$ & $0.2326^{*}$ & $0.2881^{* *}$ & $0.3494^{* *}$ & $0.2022^{*}$ \\
\hline
\end{tabular}

status to a milder status, $\mathrm{n}=110$ ) had a total mean modified PEI score of 6.32 [Interquartile range 3-10]. Those whose asthma status did not change $(n=98)$ had a total mean modified PEI score of 5.61 [Interquartile range 3-8]. In those whose asthma status deteriorated $(n=18)$ the mean score was 4.72 [Interquartile range 1-7]. There was no statistically significant association (Kruskal-Wallis test $P$ for association $=0.17$ ), but a trend towards a correlation is apparent.

With a scoring range of $0-2$ for each question, a total range of $0-12$, and a Cronbach's alpha score of $>0.9$, the possibility of ceiling and floor effects arises. Adapting the scoring system by replacing a score of 0 ("same or less") with -1 or -2 did not significantly improve the discriminatory properties.

A significantly greater proportion of patients using the adjustable asthma treatment regime had a modified PEI total score of $\geq 6$ compared with patients receiving the fixed dose treatment regime $(57 \%[n=70 / 123]$ versus $43 \%[n=45 / 104], p=0.04)$.

\section{Discussion}

The original $\left.\mathrm{PEI}\right|^{2}$ has been extensively used and is widely accepted as being fit for its primary purpose. This study suggests that, with a simple change to the introductory statement, the modified PEI demonstrates internal consistency and external validity in the setting of the long-term management of asthma comparable to the original PEI in its original setting. In this large study of 228 patients in 72 centres, we have demonstrated that improvement in the modified PEI was associated with clinical improvement as measured by the AQLQ. The tool can also identify a significant difference in "enablement" between a cohort "enabled" by having the skills and permission to adjust their medication without immediate reference to a clinician, and a control group taking a regular, fixed dose of medication. We propose that this is a valid and appropriate outcome measure to consider in the long-term management of asthma. 
The correlation between the modified PEI total score and AQLQ is low at 0.13 . This demonstrates that the modified PEI is sufficiently different from the Mini AQLQ to be measuring something other than quality of life, but the significant correlation between the modified PEI and the change in Mini AQLQ (overall and all domain scores) suggests the $\mathrm{PEI}$ is responsive to a change in a patient's quality of life, or vice versa.

However, there remain issues to be addressed. The first of these is internal consistency. The Cronbach's alpha score of 0.92 in this study is similar to the figure reported in the original setting. ${ }^{2}$ For an individual in a clinical setting a tool with a Cronbach's alpha score of $>0.9$ is considered necessary. ${ }^{8}$ On the other hand, for scales which are used as research tools to compare groups, alpha values should be above 0.7 but not higher than $0.9 .{ }^{9} \mathrm{~A}$ very high alpha score suggests that there are repetitive, and therefore redundant, items in the questionnaire which could lead to "double counting".

The second issue is that of validity. To be valid, an outcome measure needs to show reproducibility (that the score will be similar if measured at different time points without change in the scenario) and responsiveness (that the score changes over time with meaningful change in the scenario). Neither of these attributes was tested in the original PEI work nor fully tested in this study.

Finally, to ensure that it is appropriate to modify questionnaires for use outside their original setting, we should address the issue of face validity. What is "enablement" in the chronic management of asthma? What does the word mean and to whom? Can we define it? (and therefore design a questionnaire to measure it?). If "the measure should centre on issues that patients identify as important rather than on issues that doctors believe to be important" 2 then an appreciation of patients' perception of the concept of "enablement" in the long-term management of asthma is required.

Further studies, starting with a qualitative study of patients' views leading to the development of an appropriate questionnaire, are now required.

\section{Conflict of interest declaration}

John Haughney has received fees from AstraZeneca, Boehringer Ingelheim and Merck Sharp \& Dohme for speaking at meetings, and from AstraZeneca, GlaxoSmithKline, Merck Sharp \& Dohme, Novartis and Schering Plough for consulting.
Philip Cotton has spoken at meetings for AstraZeneca but has not received personal fees for doing so.

Jan-Paul Rosen and Ken Morrison are full time employees of AstraZeneca UK Ltd.

David Price has no shares in pharmaceutical companies. He has received speaker's honoraria for speaking at sponsored meetings from the following companies marketing respiratory products: 3M, Altana, AstraZeneca, BI, GSK, IVAX, MSD, Novartis, Pfizer, Schering Plough. He has received honoraria for advisory panels from: $3 \mathrm{M}$, Altana, AstraZeneca, BI, GSK, IVAX, MSD, Novartis, Pfizer and Schering Plough. He or his research team have received funding for research projects from: 3M, Altana, AstraZeneca, BI, GSK, IVAX, MSD, Novartis, Pfizer, Schering Plough and Viatris.

\section{Funding}

This study was funded by AstraZeneca UK.

\section{References}

1. British Thoracic Society, Scottish Intercollegiate Guideline Network. British Guideline on the management of asthma. Thorax 2003;52:S1-S28.

2. Howie JG, Heaney DJ, Maxwell M, Walker JJ. A comparison of a Patient Enablement Instrument (PEI) against two established satisfaction scales as an outcome measure of primary care consultations. Fam Pract 1998;15(2):165-71.

3. Howie JGR, Heaney DJ, Maxwell M. Measuring Quality in General Practice. Occasional Paper London: Royal College of General Practitioners 1997;75:1-32.

4. Dowell J, Pitkethly M, Bain J, Martin S. A randomised controlled trial of delayed antibiotic prescribing as a strategy for managing uncomplicated respiratory tract infection in primary care. $\mathrm{Br} J$ Gen Pract 2001; 51(464):200-05.

5. Howie JG, Heaney DJ, Maxwell M. Care of patients with selected health problems in fundholding practices in Scotland in 1990 and 1992: needs, process and outcome. Br J Gen Pract 1995;45(392):121-6.

6. Ind PW, Haughney J, Price D, Rosen JP, Kennelly J. Adjustable and fixed dosing with budesonide/ formoterol via a single inhaler in asthma patients: the ASSURE study. Respir Med 2004;98(5):464-75.

7. National Institutes for Health NHLBI. Global strategy for asthma management and prevention. Global Initiative for Asthma (GINA). Publication Number 02-3659, 20022002.

8. Bland JM, Altman DG. Statistics notes: Cronbach's alpha. BMJ 1997;314(7080):572.

9. Fitzpatrick R, Davey C, Buxton MJ, Jones DR. Evaluating patient-based outcome measures for use in clinical trials. Health Technol Assess 1998;2(14):i-74.

Available online at http://www.thepcrj.org 